\title{
PERANCANGAN APLIKASI SIMULASI UJIAN NASIONAL BERSTANDAR KOMPUTER BERBASIS WEB DI SDS MENTARI JAKARTA BARAT
}

\author{
Intan Fetriany $^{1}$, I Agus Sobari ${ }^{2}$ \\ ${ }^{1,2}$ Program Studi Teknik Informatika STMIK Nusa Mandiri Jakarta \\ Jl. Kamal Raya No. 18 Ring Road Barat, Cengkareng, Jakarta Barat, Indonesia \\ E-mail : ifetry@gmail.com ${ }^{1}$, irwan.igb@ nusamandiri.ac.id ${ }^{2}$
}

\begin{abstract}
ABSTRAK
Dalam melakukan evaluasi hasil belajar siswa selama menjalani pendidikan di sekolah, Menteri Pendidikan dan Kebudayaan mengeluarkan Peraturan Nomor 1 Tahun 2017 yang berisi tentang penegasan kembali pelaksanaan Ujian Nasional tahun ajaran 2016/2017 yang akan diprioritaskan menjadi Ujian Nasional Berbasis Komputer (UNBK). Dengan sistem UNBK ini, tentunya siswa-siswi membutuhkan pembekalan khusus dalam menghadapi UNBK yang diadakan oleh pihak sekolah. Teknologi komputer dalam dunia pendidikan saat ini memiliki peran yang sangat penting untuk meningkatkan kreatifitas siswa-siswi dan mampu memudahkan pekerjaan, namun masih ada beberapa lembaga pendidikan yang belum menggunakan teknologi komputer contohnya di SDS MENTARI. Semua pekerjaan masih dilakukan secara manual membuat guru mengalami kesulitan dan hasil yang diperoleh memerlukan waktu yang cukup lama, misal pada kasus kali ini yaitu proses ujian, mengoreksi hasil ujian dan pencarian data siswa-siswi yang masih menggunakan cara manual. Pada kali ini penulis melakukan observasi, wawancara dan studi pustaka di SDS MENTARI, selain itu metode yang digunakan untuk pengembangan sistem menggunakan analisa kebutuhan sistem, desain, code generation, testing dan support.
\end{abstract}

Kata kunci : UNBK, Teknologi, Simulasi

\section{PENDAHULUAN}

Semakin berkembangnya zaman, teknologi semakin maju dan banyak diperlukan dalam hal apapun. Teknologi komputer sangat dibutuhkan manusia sebagai suatu hal yang berguna dan membantu suatu pekerjaan dalam berbagai hal termasuk di dunia Pendidikan. Teknologi dalam dunia Pendidikan sangatlah berguna, salah satu nya mengenai ujian sekolah yang bertujuan agar siswa-siswi dapat memahami tentang teknologi dan internet serta dapat menggunakan komputer dengan baik dan benar.

Dalam melakukan evaluasi hasil belajar siswa-siswi selama menjalani pendidikan sekolah, Pemerintah mengeluarkan Kebijakan Ujian Nasional (UN) sebagai alat ukur kompetensi siswa-siswi guna meningkatkan mutu pendidikan di Indonesia. Dengan Peraturan Menteri Pendidikan dan Kebudayaan tentang Ujian Nasional Berstandar Komputer (UNBK), tentu hal baru bagi siswa-siswi yang belum terbiasa dengan penggunaan komputer. Dengan sistem UNBK tentu nya, siswa-siswi membutuhkan simulasi dalam menghadapi UNBK yang diadakan oleh pihak sekolah. [1]

Penyelenggaraan sistem ujian online dengan jaringan lokal sekolah merupakan hasil evaluasi pembelajaran siswa-siswi. Sistem ujian online ini digunakan untuk mempermudah proses ujian dan penilaian hasil ujian siswa. Dulu evaluasi belajar dilakukan secara manual dengan menggunakan lembar jawaban berupa kertas dengan sistem pembulatan jawaban yang sedikit rumit dan membuang waktu dan biaya. Dengan adanya sistem ujian online ini diharapkan proses ujian dan penilaian siswa dapat lebih mudah dan menghasilkan data yang cepat, tepat dan akurat. [2]

Dengan berkembangnya teknologi, sistem ujian secara manual diubah menjadi sistem ujian berstandar komputer. Adapun keuntungan dari pelaksanaan ujian berstandar komputer yaitu kecepatan dan kemudahan dalam proses pemberian nilai akhir. Penguji tidak melakukan pemeriksaan secara manual pada lembar jawaban peserta kemudian menghitung nilai, melainkan nilai telah ada di perangkat lunak basis data dengan melakukan penghitungan otomatis berdasarkan jawaban benar peserta. Keuntungan lainnya yaitu penghematan penggunaan kertas dan berkurangnya bentuk kecurangan yang dilakukan peserta, serta waktu dan tempat 
pelaksanaan ujian dapat diatur sehingga menyulitkan para peserta untuk bertindak curang. [3]

Sama halnya dengan sekolah dasar yang lain, SDS Mentari juga ingin menerapkan kemajuan tersebut dalam sistem komputerisasi. Dengan adanya perangkat komputer sebagai alat bantu, maka semua kegiatan dapat dikelola dengan baik menggunakan komputer.

Tujuan dari penelitian ini adalah untuk memudahkan para guru dalam memeriksa soal dan untuk menghemat waktu serta untuk memperkenalkan sistem ujian online kepada siswa tingkat sekolah dasar. Berdasarkan hasil analisis di SDS Mentari, masih menggunakan cara manual yang membuang waktu banyak. Metode yang digunakan untuk mengumpulkan data adalah dengan melakukan observasi, wawancara dan studi pustaka sedangkan untuk metode pengembangan sistem menggunakan metode waterfall.

\section{HASIL DAN PEMBAHASAN}

\subsection{Kajian Teori}

Berikut adalah pembahasan mengenai kajian teori yang digunakan dalam Perancangan Aplikasi Simulasi Ujian Nasional Berstandar Komputer Berbasis Web di SDS Mentari Jakarta Barat.

\subsubsection{Pengertian Sistem}

Sistem adalah kumpulan dari dua atau lebih komponen yang saling berhubungan satu sama lain untuk mencapai tujuan tertentu. [4]

\subsubsection{Pengertian Database}

Database adalah sekumpulan data store (data yang bisa dalam jumlah yang sangat besar) tersimpan didalam magnetic disk, optical disk, magnetic drum atau media penyimpanan sekunder lainnya yang bisa dikelola dan saling berkaitan satu sama lain atau berhubungan. [5]

\subsubsection{Pengertian Internet}

Internet adalah jaringan komunikasi yang melibatkan banyak komputer pribadi dengan menggunakan protokol Transmission Control Protocol/Internet Protocol (TCP/IP) yang memungkinkan komunikasi antar komputer lain dengan jarak yang tidak ditentukan. [5]

\subsubsection{Pengertian Website}

Web atau website adalah kumpulan dhalaman situs dan dokumen yang tersebar dibeberapa komputer server yang berada di seluruh dunia dan terhubung menjadi suatu kesatuan jaringan yang disebut internet. [4]

\subsubsection{Pengertian Web Browser}

Web browser adalah program untuk menampilkan dan mengetest hasil program. Semua halaman situs web ditulis dengan bahasa HTML (Hypertext Mark Up Language), walaupun banyak file yang mempunyai ekstensi berbeda-beda, namun output file-file tersebut tetap HTML. [6]

\subsubsection{Bahasa Pemrograman}

Bahasa Pemrograman adalah notasi untuk memberikan perintah kepada komputer. [7] Berikut ini adalah bahasa pemrograman yang digunakan dalam Perancangan Aplikasi Simulasi Ujian Nasional Berstandar Komputer Berbasis Web di Sds Mentari Jakarta Barat, yaitu:

a. PHP (Hypertext Preprocessor)

PHP atau Hypertext Preprocessor merupakan bahasa yang dapat digunakan sebagai bahasa skrip serverside dalam pengembangan web yang dapat disisipkan pada dokumen HTML. [5]

b. CSS (Cascading Style Sheets)

CSS atau Cascading Style Sheets adalah skrip yang digunakan untuk memberi atau mengatur desain pada website. [8] Fungsi dari CSS yaitu untuk memberikan berbagai pengaturan lengkap agar website lebih terlihat menarik dan bagus. [8]

c. JavaScript

JavaScript adalah bahasa skrip yang ditempatkan pada kode HTML dan hanya diproses pada sisi klien. [5] Peran penting JavaScript adalah untuk memberikan efek animasi yang menarik oleh pengguna website. [8]

d. MySQL

MySQL adalah sebuah program database server yang mampu menerima dan mengirimkan data dengan cepat menggunakan perintah standar SQL (Structured Query Language). [5]

e. PHP MyAdmin

PHP MyAdmin merupakan aplikasi web yang dapat diakses menggunakan url yang tersedia di server PHP seperti XAMPP maupun server profitabel lainnya. [9]

\section{f. XAMPP}

XAMPP adalah sebuah aplikasi perangkat lunak pemrograman dan database yang didalamnya terdapat berbagai macam aplikasi pemrograman seperti: Apache HTTP server, MySQL, database dan Bahasa Pemrograman PHP. [9] 


\subsubsection{UML (Unified Modeling Language)}

Unified Modeling Language (UML) adalah struktur dan teknik yang didukung oleh model tunggal yang membantu mendeskripsikan dan mendesain sistem software, khususnya untuk sistem yang digunakan membangun pemrograman berorientasi objek. [10] Yang termasuk dalam Diagram UML, yaitu:

a. Use Case Diagram

Use case diagram adalah teknik untuk merecord syarat fungsional oleh sebuah sistem dan mendeskripsikan hubungan antara para pengguna sistem dengan sistem itu sendiri. [11]

b. Activity Diagram

Activity diagram (diagram aktivitas) adalah teknik untuk menggambar logika prosedur, proses bisnis dan alur kerja. Dalam beberapa hal, diagram ini memainkan peran mirip sebuah diagram alir. [11]

c. Sequence Diagram

Sequence diagram merupakan diagram yang menunjukkan kelompok objek yang saling bekerjasama dalam beberapa tindakan. [11]

d. Deployment Diagram

Deployment diagram merupakan susunan secara fisik dari sebuah sistem, yang menegaskan bagian pada software berjalan pada hardware yang sedang bekerja. [11]

\subsubsection{ERD (Entity Relationship Diagram)}

Entity Relationship Diagram (ERD) merupakan model jaringan data yang memfokuskan pada struktur dan hubungan data jaringan yang menjelaskan tentang data yang tersimpan (storage data) dalam sistem. [5]

\subsection{Metode Penelitian}

Berikut adalah pembahasan mengenai metode penelitian yang digunakan dalam Perancangan Aplikasi Simulasi Ujian Nasional Berstandar Komputer Berbasis Web di SDS Mentari Jakarta Barat.

\subsubsection{Metode Pengumpulan Data}

Teknik pengumpulan data yang digunakan dalam penelitian ini, yaitu:

\section{a. Observasi}

Proses pengumpulan data yang dilakukan dengan cara melakukan pengamatan langsung ke tempat tujuan. Penulis melakukan pengamatan atau observasi di SDS Mentari Jakarta Barat dengan mengambil data-data yang diperlukan dalam pembuatan Skripsi ini, sehingga penulis mendapatkan data dan informasi mengenai simulasi unbk berbasis web.

b. Wawancara

Proses yang dilakukan dengan bertanya langsung atau melakukan tanya jawab untuk mendapatkan informasi akurat kepada Ibu Sumaria selaku Kepala Sekolah SDS Mentari Jakarta Barat.

c. Studi Pustaka

Dalam teknik pengumpulan data ini, penulis melakukan studi ke perspustakaan dan mencari referensi dari buku dan internet untuk mencari sumber referensi yang dibutuhkan.

\subsubsection{Metode Pengujian}

Metode pengujian yang dipakai yaitu dengan metode BlackBox Testing. Metode Blackbox Testing merupakan salah satu metode yang mudah digunakan karena hanya memerlukan batas bawah dan batas atas dari data yang di harapkan. Dengan metode ini dapat diketahui jika fungsionalitas masih dapat menerima masukan data yang tidak diharapkan. [12]

\subsubsection{Metode Pengembangan Sistem}

Metode pengembangan sistem yang digunakan yaitu waterfall model. Model waterfall adalah model pengembangan perangkat lunak yang menggunakan fase yang berurutan. [13]. Dengan tahapan sebagai berikut:

a. Analisa Kebutuhan Sistem

Membuat analisa dan perancangan pada sistem simulasi ujian. Siswa dapat melakukan login, mengerjakan soal secara online dan melihat hasil dari simulasi ujian tersebut.

b. Desain

Sistem ujian nasional berstandar komputer dan berbasis web atau internet menggunakan bahasa Pemrograman web PHP serta database MYSQL dan desain sistem dibuat menggunakan UML (Use Case Diagram, Activity Diagram, Squence Diagram dan Deployment Diagram), ERD (Entity Relation Diagram) dan LRS (Logical Record Structure).

c. Code Generation

Menggunakan jenis bahasa Program PHP, MYSQL, CSS dan HTML serta program dibuat secara terstruktur.

\section{d. Testing}

Pada bagian testing, penulis menggunakan Black Box testing dengan melakukan uji coba sistem untuk mengetahui kelayakan sistem. Apabila sistem bekerja dengan baik dan benar, maka sistem layak untuk digunakan dalam melakukan simulasi ujian nasional berstandar komputer berbasis web ini. 
e. Support

Support atau pemeliharaan adalah kegiatan pemeliharaan terhadap data soal yang akan ditampilkan dalam sistem simulasi ujian ini.

\subsection{Hasil dan Pembahasan}

Berikut adalah pembahasan dari hasil analisis dan perancangan pada Perancangan Aplikasi Simulasi Ujian Nasional Berstandar Komputer Berbasis Web di SDS Mentari Jakarta Barat.

\subsubsection{Perancangan Sistem}

Perancangan aplikasi simulasi ujian nasional berstandar komputer berbasis web di Sds Mentari Jakarta Barat ini dibuat untuk menggambarkan perancangan sistem yang diusulkan mulai dari halaman home sampai halaman log-out.

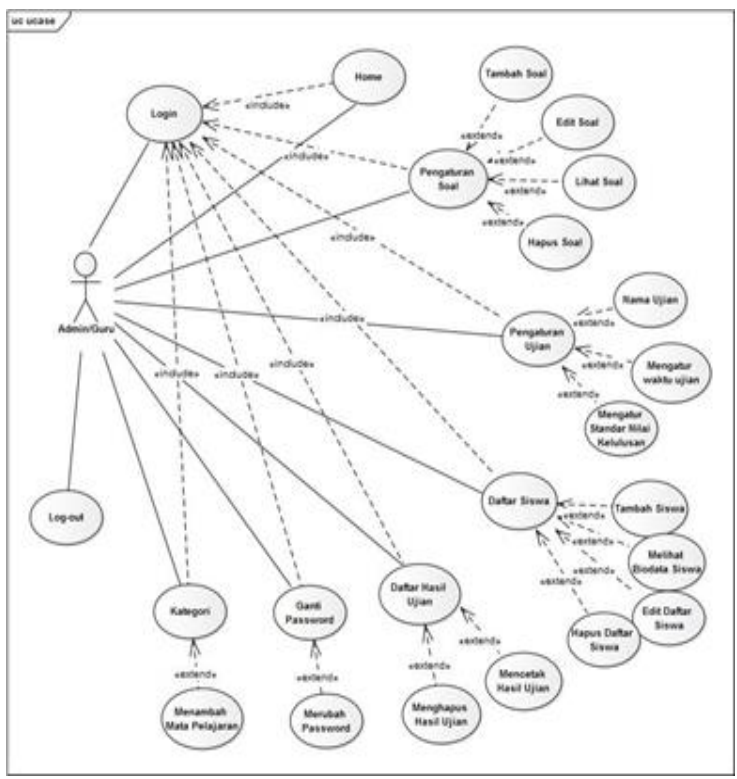

Gambar 1. Use Case Diagram Admin/Guru

Gambar 1 merupakan fasilitas atau menu yang terdapat didalam web home administrator. Yang dapat mengakses yaitu admin dan guru. Dalam mengakses sistem, semua aktor harus melakukan login dengan menggunakan username dan password yang telah didaftarkan di sistem tersebut. Untuk admin dan guru, apabila sudah melakukan login bisa mengakses halaman web tersebut. Halaman tersebut berisi tabel home yang berisi tentang maksud dari web tersebut. Halaman tabel pengaturan soal terdiri dari tabel tambah soal, tabel edit soal, tabel lihat soal dan tabel hapus soal. Halaman tabel pengaturan ujian berisi tentang tabel pengaturan nama mata pelajaran atau kategori ujian, tabel pengaturan nilai minimal standar kelulusan dan tabel pengaturan waktu ujian. Halaman daftar siswa terdiri dari tabel tambah siswa, tabel hapus siswa, tabel melihat biodata siswa dan tabel edit daftar siswa. Halaman daftar ujian terdiri dari tabel mencetak hasil ujian siswa dan tabel menghapus hasil ujian. Halaman ganti password berisi tabel untuk mengubah password admin. Dan di halaman kategori berisi tabel untuk menambah kategori atau mata pelajaran.

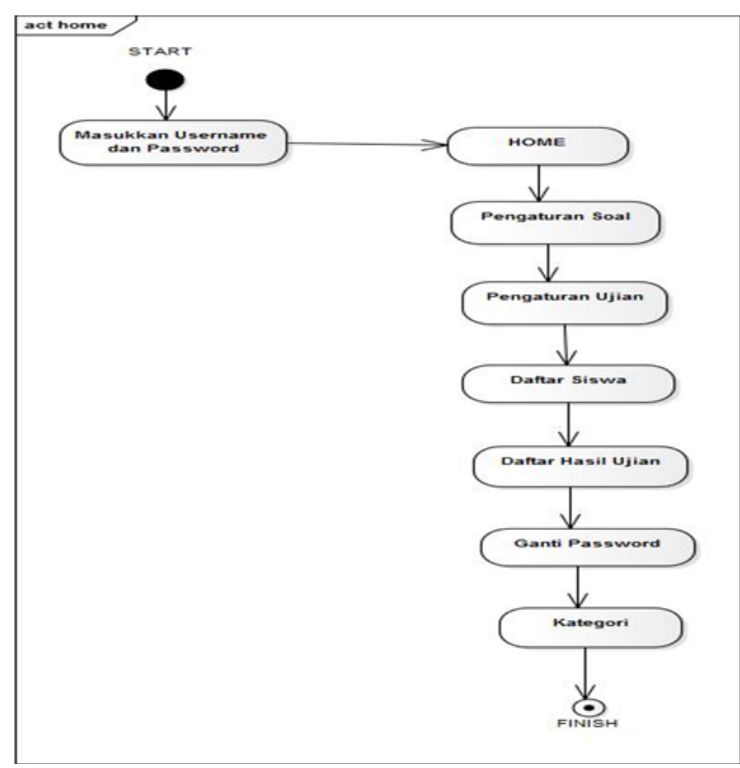

Gambar 2. Activity Diagram Home Admin

Gambar 2 menggambarkan aktifitas dari menu home yang dapat dilakukan di menu home atau beranda yang dimulai dari admin melakukan login, lalu masuk ke sistem dan mengklik tombol home. Jika admin ingin melakukan pengaturan soal maka admin mengklik tabel pengaturan soal. Jika soal sudah ditambah, di edit atau dihapus lalu klik simpan. Apabila admin ingin melakukan pengaturan ujian maka admin mengklik tabel pengaturan ujian. Jika semua tabel telah diubah admin bisa keluar dari sistem.

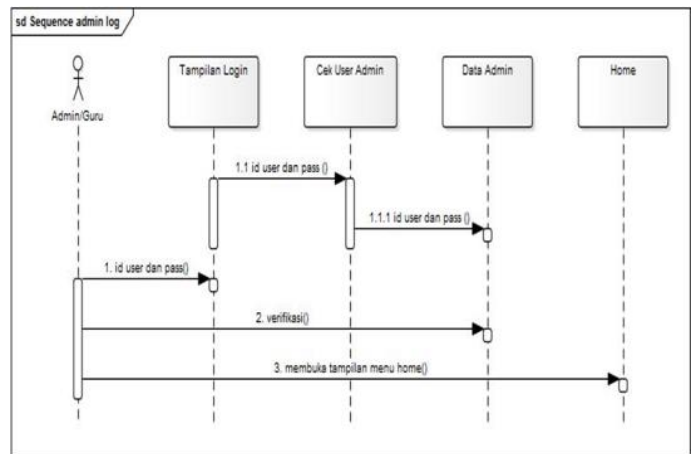

Gambar 3. Sequence Diagram Halaman Home Admin 
Gambar 3 menggambarkan aktifitas admin dalam berinteraksi dengan sistem. Admin melakukan login dengan membuka form login dan memasukkan username dan password, kemudian sistem akan mengecek username dan password tersebut. Jika username dan password tersebut benar, sistem akan langsung masuk ke menu home apabila username dan password salah sistem akan langsung balik ke form login dan menampilkan pop-up username dan password salah.

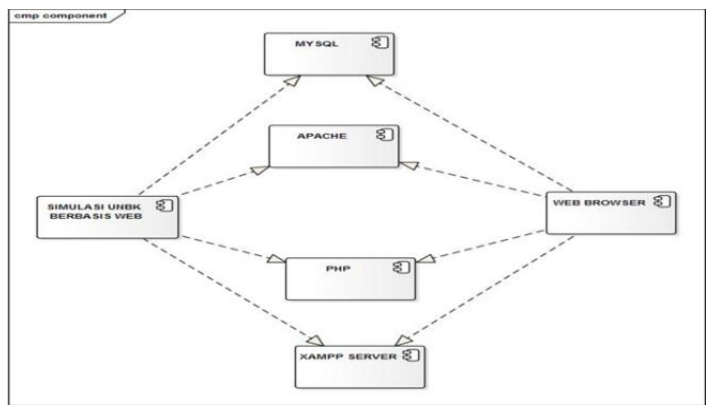

Gambar 4. Component Diagram

Gambar 4 merupakan aplikasi yang dibangun yaitu Program Simulasi Ujian Nasional Berstandar Komputer Berbasis Web, aplikasi ini dibuat dengan menggunakan Bahasa Pemrograman PHP dan menggunakan database server nya yaitu MYSQL dengan server tampilan halaman web yaitu XAMPP SERVER dan untuk database nya yaitu db_sekolah.

\subsubsection{Desain Database}

a. Entity Relationship Diagram (ERD)

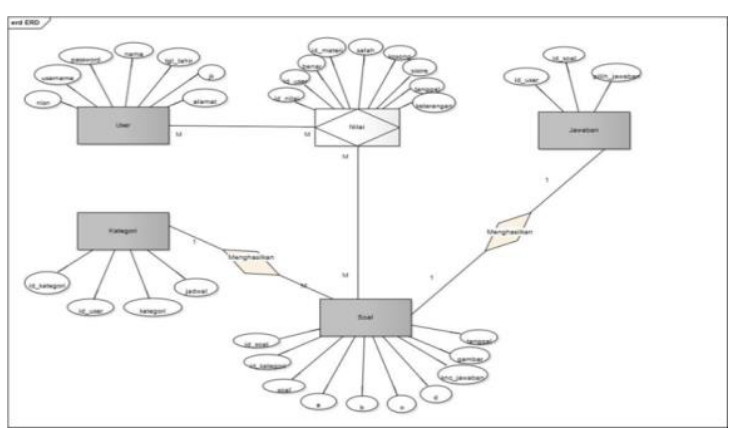

Gambar 5. ERD Simulasi Ujian Nasional

Gambar 5 menggambarkan Simulasi Ujian Nasional Berbasis Web dibangun berdasarkan 5 entitas yaitu entitas user, nilai, jawaban, kategori dan soal. Kelima entitas tersebut memiliki atribut masing-masing, untuk entitas user atributnya terdiri dari nisn, username, password, nama, tgl_lahir, jk dan alamat. Untuk entitas nilai terdiri dari id_nilai, id_user, benar, id_materi, salah, kosong, score, tanggal dan keterangan. Untuk entitas jawaban terdiri dari id_user, id_soal dan pilih_jawaban. Untuk entitas kategori terdiri dari id_kategori, id_user, kategori dan jadwal. Dan untuk entitas soal terdiri dari id_soal, id_kategori, soal, a, b, c, d, knc_jawaban, gambar dan tanggal.

Dari kelima entitas memiliki hubungan atau relasi dari entitas satu dengan entitas lainnya. Seperti yang digambarkan diatas bisa dilihat bahwa entitas user dengan nilai memiliki relasi many to many, kemudian entitas nilai dengan soal memiliki relasi many to many, entitas jawaban dengan soal memiliki relasi one to one dan entitas kategori dengan soal memiliki relasi one to many.

\section{b. Logical Record Structure (LRS)}

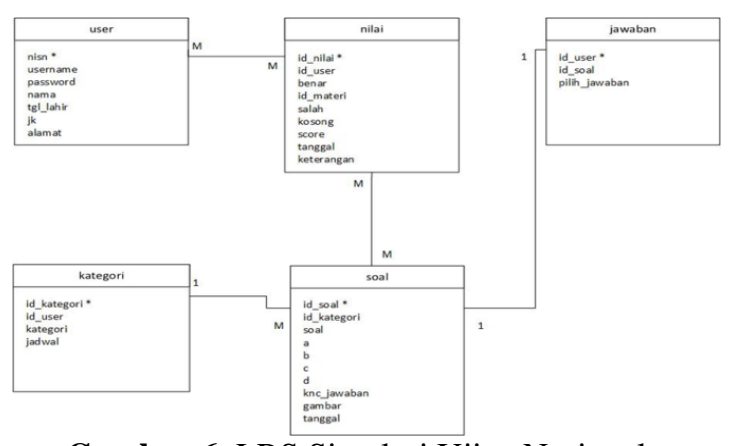

Gambar 6. LRS Simulasi Ujian Nasional

Gambar 6 menggambarkan LRS yang dibangun pada Simulasi Ujian Nasional Berbasis Web yang didapat dari pengolahan ERD, dari lima entitas yang dipakai di ERD kemudian ditransformasikan kedalam bentuk table, maka didapat lima table yang akan digunakan dalam membangun aplikasi simulasi ujian nasional berstandar komputer berbasis web yaitu table user, table nilai, table jawaban, table kategori dan table soal. Kemudian untuk atribut akan ditransformasikan menjadi field untuk membangun table sedangkan relasi tiap table masih sama dengan ERD.

\section{Implementasi Dan Pengujian Sistem}

\subsection{Implementasi Sistem}

Tahap implementasi sistem merupakan tahap pengaplikasian dari perancangan yang akan dilakukan berdasarkan analisis sistem sebelumnya. Diimplementasikan kedalam bahasa pemrograman yang telah ditentukan dan penerapan sistem yang akan dibangun pada sebuah aplikasi. Pembahasan implementasi yang akan dibahas dalam jurnal penelitian ini adalah implementasi user interface. 


\subsection{Implementasi User Interface}

Interface adalah salah satu bagian terpenting dalam sebuah sistem yang dirancang untuk mengelola input dan output dari data. User interface merupakan tampilan antar muka user (pengguna) yang merupakan mekanisme komunikasi antar user (pengguna) dengan sistem. Antar muka pemakai (user interface) dapat digunakan untuk menerima informasi kepada pengguna user untuk membantu sebuah masalah sampai ditemukan suatu solusi.

Berikut ini merupakan tampilan interface atau tampilan antarmuka dari perancangan aplikasi simulasi ujian nasional berbasis web yang dirancang dan diterapkan di SDS MENTARI Jakarta Barat:

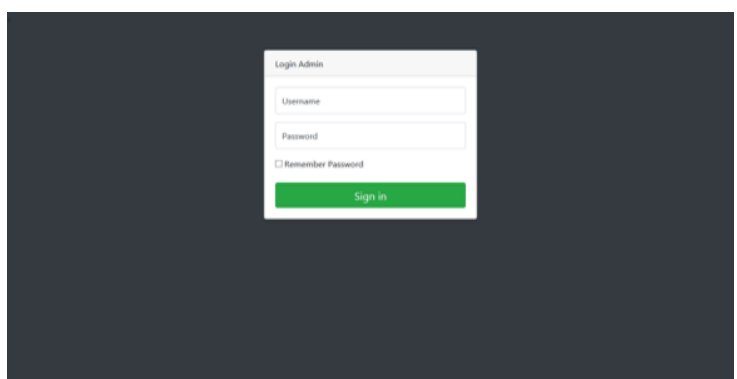

Gambar 7. Halaman Login

Gambar 7 merupakan halaman form login dan buton untuk membuka home dashboard dari simulasi ujian nasional berbasis web.

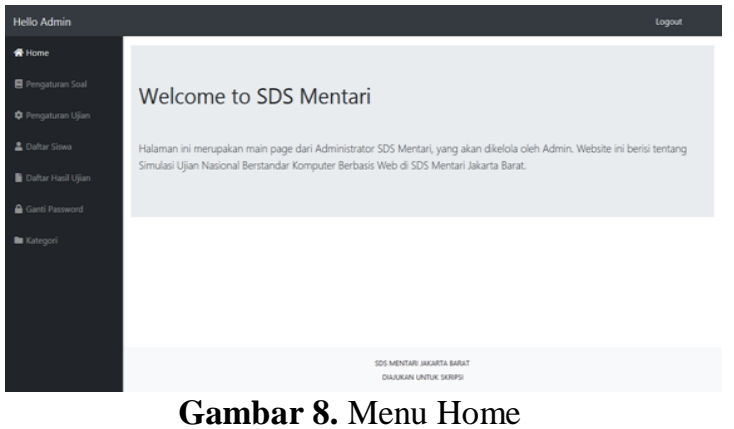

Gambar 8 merupakan halaman home dimana pada halaman tersebut terdapat menu pengaturan soal, pengaturan ujian, daftar siswa, daftar hasil ujian, ganti password dan menu kategori.

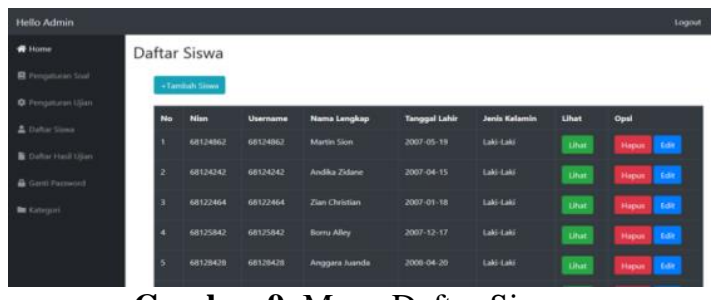

Gambar 9. Menu Daftar Siswa
Gambar 9 merupakan halaman menu daftar siswa yang mempunyai fungsi untuk menambah siswa, menghapus siswa, melihat biodata siswa dan mengubah biodata siswa.

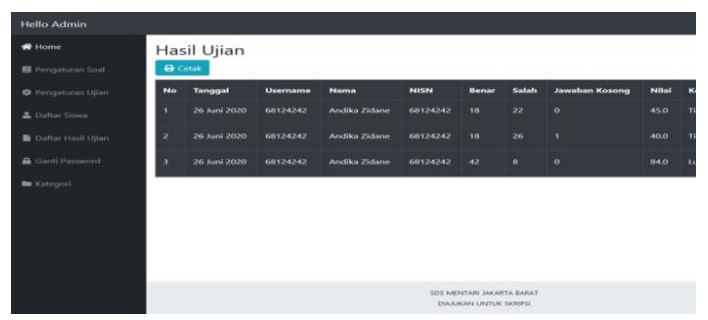

Gambar 10. Menu Daftar Hasil Ujian

Gambar 10 merupakan halaman untuk melihat hasil ujian siswa yang berfungsi untuk mencetak seluruh hasil ujian siswa dan menghapus hasil ujian siswa.

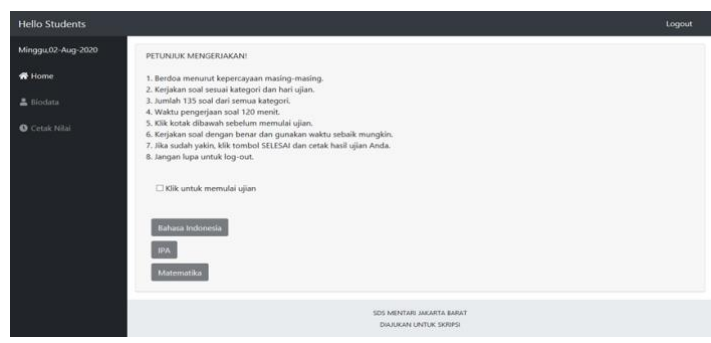

Gambar 11. Halaman Home User

Gambar 11 merupakan halaman home siswa yang berisi kategori ujian dan ketentuan ujian.

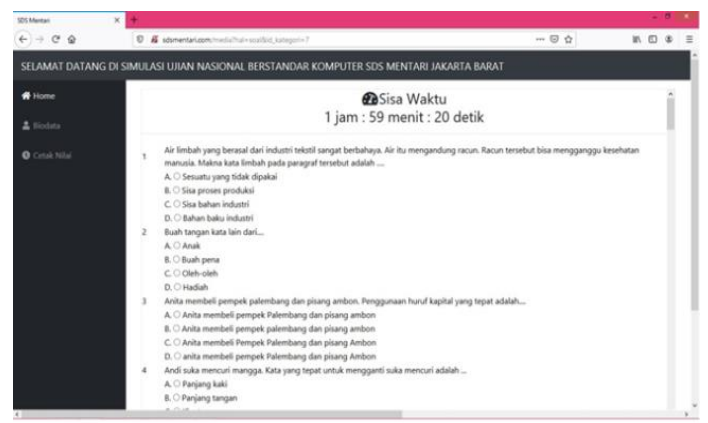

Gambar 12. Halaman Pengerjaan Soal

Gambar 12 merupakan halaman untuk user atau siswa mengerjakan soal simulasi ujian dengan waktu 2 jam sesuai mata pelajaran atau kategori nya. 


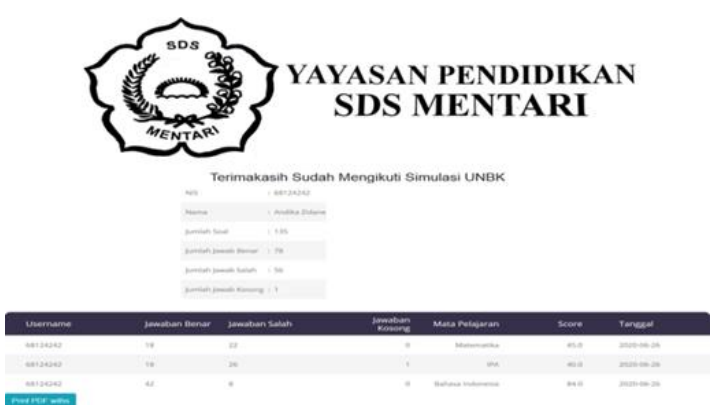

Gambar 13. Halaman Cetak Nilai

Gambar 13 merupakan gambar untuk melakukan cetak nilai siswa berdasarkan score atau nilai dari hasil ujian yang mempunyai format file pdf.

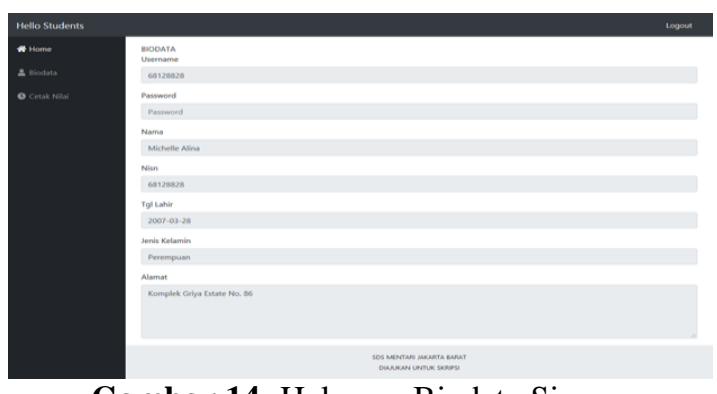

Gambar 14. Halaman Biodata Siswa

Gambar 14 merupakan gambar untuk melihat data pribadi pada halaman web user.

\section{PENUTUP}

\subsection{Kesimpulan}

Berdasarkan penelitian yang dilakukan dapat ditarik kesimpulan bahwa perancangan simulasi ujian nasional berstandar komputer berbasis web dibuat agar mempermudah para siswa dalam mengerjakan simulasi ujian online serta untuk memperkenalkan dan memberitahu tentang ujian online berstandar komputer berbasis web kepada siswa sekolah dasar dan memanfaatkan ilmu teknologi dan komputer dengan bijak.

\subsection{Saran}

Saran untuk peneliti lainnya yang ingin mengembangkan aplikasi ini agar memaksimalkan sistem yang telah dirancang karena sistem yang diusulkan masih bersifat perancangan. Perlu adanya sosialisasi antara guru dan murid untuk menggunakan web ini dengan baik. Serta sistem perancangan aplikasi ini perlu dikembangkan lebih dalam agar menjadi website yang lebih baik dengan fitur yang lebih lengkap dan mudah dipahami bagi pengguna (user friendly).

\section{DAFTAR PUSTAKA}

[1] A. U. Firmansyah, "Aplikasi Simulasi Uji Coba ( Tryout ) Ujian Nasional Berbasis Komputer ( Unbk ) Tahun 2018," Semin. Nas. R., vol. 9986, no. September, pp. 111114, 2018.

[2] W. Setyowati, W. W. Winarno, and Sudarmawan, "Analisis Penerimaan Teknologi Sistem Ujian Online Untuk," Semin. Nas. Teknol. Inf. dan Multimed. 2015, pp. 6-8, 2015.

[3] N. W. S. Saraswati and D. M. D. U. Putra, "Sistem Ujian Online Berbasis Website," S@Cies, vol. 6, no. 1, pp. 21-30, 2015, doi: 10.31598/sacies.v6i1.78.

[4] I. Ananda and E. Zuraidah, "Perancangan Sistem Informasi Penjualan Barang Pada PT Asia Truk Pratama Jakarta," J. Inform., vol. 6, no. 2, pp. 193-200, 2019, doi: 10.31311/ji.v6i2.6248.

[5] Muhamad Son Mu, "Rancang Bangun Sistem Ujian Online Pada Smp Negeri 8 Sekayu," J. Tek. Inform. Politek. Sekayu, vol. 2, no. 1, pp. 28-40, 2015, [Online]. Available: http://jurnal.polsky.ac.id/index.php/tips/artic le/view/38.

[6] M. Susanti, "Perancangan Sistem Informasi Akademik Berbasis Web Pada Smk Pasar Minggu Jakarta," Informatika, vol. 3, no. 1, pp. 91-99, 2016.

[7] A. et. a. Dewanto, Bahasa Pemrograman Untuk SMK. Jakarta: Tim, 2018.

[8] R. Abdulloh, Easy \& Simple Web Programming Belajar Pemrograman Website Secara Efektif dan Efisien. Jakarta: PT. Elex Media Komputindo, 2016.

[9] Y. M. K. - STMIK Nusa Mandiri Jakarta, I. M. - STMIK Nusa Mandiri Jakarta, and I. A. - AMIK BSI Purwokerto, "Sistem Informasi Akademik Berbasis Web Pada Smk Negeri 2 Banyumas," Evolusi J. Sains dan Manaj., vol. 5, no. 2, pp. 82-89, 2017, doi: 10.31294/evolusi.v5i2.3128.

[10] Kadek Wibowo, "Penerapan Sistem Informasi Akademik Berbasis Web ( Studi Kasus MTs . Maulana Ishaq Banyuwangi ),” 
AMIK Bina Sarana Inform. Jakarta, pp. 119124, 2015.

[11] M. Fowler, UML DISTILLED, 1st ed. Yogyakarta: Tim Penerbit ANDI, 2015.

[12] W. N. Cholifah, Y. Yulianingsih, and S. M. Sagita, "Pengujian Black Box Testing pada Aplikasi Action \& Strategy Berbasis Android dengan Teknologi Phonegap," STRING (Satuan Tulisan Ris. dan Inov. Teknol., vol. 3, no. 2, p. 206, 2018, doi: 10.30998/string.v3i2.3048.
[13] A. Hirmawan, M. P, and D. Azizah, "ANALISIS SISTEM AKUNTANSI PENGGAJIAN DAN PENGUPAHAN KARYAWAN DALAM UPAYA MENDUKUNG PENGENDALIAN INTERN (Studi pada PT.Wonojati Wijoyo Kediri)," J. Adm. Bisnis S1 Univ. Brawijaya, vol. 34, no. 1, pp. 189-196, 2016. 